\title{
Specificity and Definiteness in Sentence and Discourse Structure*
}

\author{
Klaus von Heusinger \\ Universität Konstanz \\ klaus.heusinger@uni-konstanz.de
}

\section{Introduction}

Indefinite expressions show a contrast in readings that can be informally illustrated by example (1). The indefinite NPs a monk and something have readings that contrast with the readings of serpents, headless men or men with two heads, besides the contrast between singular and plural. This contrast is captured by terms specific and non-specific, respectively:

(1) "But in the abbey there are rumors,...strange rumors..."

"Of what sort?"

"Strange. Let us say, rumors about a monk who decided to venture into the library during the night, to look for something Malachi had refused to give him, and he saw serpents, headless men, and men with two heads. He was nearly crazy when he emerged from the labyrinth..." (89)

A specific reading of an indefinite NP is pretheoretically characterized by the "certainty of the speaker about the identity of the referent", "the speaker has the referent in mind", "the speaker can identify the referent", etc. Another version of this characterization is that the referent of a specific NP is fixed or determined before the main predication is computed and that it matters which referent we select out of the set of entities that fulfill the description. It is generally assumed that specific indefinites are "scopeless" like proper names or demonstratives, i.e. they always show widest scope, and therefore are assumed to be existentially presupposed. Furthermore, the insertion of a certain indicates specificity.

Pretheoretical and informal characterization of specificity

(i) certainty of the speaker about the identity of the referent

(ii) the referent is fixed / determined / not depending on the interpretation of the matrix predicate

(iii) specific indefinite NPs are "scopeless" or "referential terms", i.e. they behave as if they always have the widest scope

(iv) specific indefinite NPs are referential terms, i.e., they are existentially presupposed

(v) specific indefinite NPs can be paraphrased by a certain ${ }^{1}$

The paper is submitted to a special issue of "Journal of Semantics".

1 There is more lexical material that can disambiguate the contrast: Haspelmath (1997) investigates indefinite pronouns, like someone, anyone, crosslinguistically. He $(1997,38)$ observes that "it is not uncommon for languages to have two different indefinite series for specific and non-specific". Prince (1981) discusses the use of English this as an specific indefinite article. 
In this paper, I argue that this informally given list of characteristics covers only a certain subclass of specific indefinites. While most theories of specificity assume all assumptions in (2), my own proposal is based on the assumptions (2ii) and (2v), while I refute assumptions (2i), (2iii) and (2iv) as too general (in many, but not all cases, these characteristics follow from the assumptions (2ii) and (2v)). In particular, I dispute the definition of specific indefinites as "the speaker has the referent in mind" as rather confusing if one is working with a semantic theory. Furthermore, I discuss "relative specificity", i.e. cases in which the specific indefinite does not exhibit wide, but intermediate or narrow scope behavior. Based on such data, I argue that specificity expresses a referential dependency between introduced discourse items. Informally speaking, the specificity of the indefinite expression something in (1) expresses that the reference of the expression depends on the reference of another expression, here, on the expression a monk, not the speaker. On the other hand, the specific reading of a monk in (1) depends on its anchoring on the speaker. Once we have determined the reference of a monk we have also established the reference of something. I therefore introduce the term "referential anchoring" to define the semantic function of specificity.

Some of the examples for illustrating specificity are taken from the novel "The Name of the Rose" by Umberto Eco, such as (1). The novel forms the background for the sentences under investigation and controls the referential properties of the context. I also use translations of one of the same sentences as cross-linguistic evidence for grammatical reflexes of semantic distinction (for a more detailed account toward this contrastive method, see von Heusinger 2001).

The paper is organized as follows: In section 2, I discuss the often found description of specific NPs as a subclass of indefinite NPs as "known/identifiable to the speaker" as inadequate. Modern semantic theories have shown (since Karttunen 1976) that definiteness cannot be explained with recourse to identifiability - so this should not be done for specificity. In section 3, I discuss the morphological marking of specificity in Turkish. I assume that the specificity marker in Turkish is more reliable than the indirect marking in languages such as English or Italian. In section 4, I present different instances of what are called specific cases, such as scopal specificity, epistemic specificity, partitive specificity, and relative specificity. In section, 5, I present three families of semantic approaches to definiteness and specificity: the pragmatic approach assumes that specificity is a question of scope and additional pragmatic information from the early beginnings, this "additional" information is also represented as a semantic structure, see Jackendoff's (1972) "modal structure". The lexical ambiguity approach assumes that there are two indefinite articles, an existential and a referential, which then yield non-specific and specific readings, respectively. Discourse theories present definiteness as familiarity, but do not treat specific indefinites in particular. Extension of discourse theories try to capture the specificity contrast. However, all these theories are restricted with respect to the phenomena they describe. This is shown with data from Turkish - there are more cases of morphological marking of specificity than these theories predict.

In section 6 , I present a more general theory of specificity that is based on the notion of "referential anchoring" at the level of discourse representation: a specific NP is anchored to another discourse entity. Thus, the specific expression is assigned the same scope as its anchor. 


\section{Specificity and definiteness}

In this section, I discuss the relation between definiteness and specificity; in particular I argue first that specificity is not a simply a subcategory of indefinite NPs, but an independent category that can therefore form a cross-classification. Second I motivate that specificity is to be analyzed in terms of an additional structure which I call "referential struccure" of a text.

The category "specificity" was introduced for indefinite NPs as an analogy to the category "referentiality" for definite NPs. Quine (1960, $\$ 30,141 \mathrm{ff})$ discusses the referential properties of definite NPs on examples like (3): The definite NP the dean behaves differently in the scope of an intensional verb like look for. He $(1960, \S 31$, 146ff) observes that a very similar ambiguity can be constructed with indefinite NPs, such as in (4). This contrast was later termed specific vs. non-specific (Baker 1966, Fillmore 1967):

(3) John is looking for the dean.

a. ... whoever it might be

b. ..., namely for Smith, who is happens to be the dean. [referential]

(4) John is looking for a pretty girl.

a. $\quad . .$. whoever he will meet, he will take her to the movies [non-specific]

b. $\quad$..., namely for Mary.

[specific]

The intuitive concept of specificity (see (2)) extremely quickly spread over the linguistic community. However it is most often understood as secondary referential property of NPs that applies only to indefinite NPs. Additionally it has become very common to describe or define specificity in terms of identifiability by speaker and hearer, as in (5). According to this view, definite NPs are used if both the speaker and hearer can identify the referent, specific indefinite NPs, if only the speaker can identify the referent, while non-specific indefinite indicates that none of them can identify the referent:

The "identifiability" criteria for definiteness and specificity

\begin{tabular}{|l|l|l|l|}
\hline identified by & $\begin{array}{l}\text { definite } \\
(+ \text { spec })\end{array}$ & $\begin{array}{l}\text { indefinite } \\
\text { spec. }\end{array}$ & $\begin{array}{l}\text { indefinite } \\
\text { non-spec }\end{array}$ \\
\hline speaker & + & + & - \\
\hline hearer & + & - & - \\
\hline
\end{tabular}

This view is often ascribed to Givón (1978), who however gives a more differentiated picture. First, he $(1978,293)$ defines specificity - what he calls 'referentiality' - in the following way:

1.1. Rereferentiality [= specificity, $\mathrm{KvH}$ ]

In the terms used her, referentiality is a semantic property of nominals. In involves, roughly, the speaker's intent to 'refer to' or 'mean' a nominal expression to have nonempty references - i.e. to 'exist' - within a particular universe of discourse. Conversely, if a nominal is 'non-referential' or 'generic' the speaker does not have a commitment to its existence with the relevant universe of discourse. Rather, in the latter case the speaker is engaged in discussing the genus or its properties, but does not commit him/herself to the existence of any specific individual member of that genus. 
In this definition, specificity is defined in terms of (i) existential presupposition (cf. (2iv)) and (ii) in terms of the type of the referent (individuals vs. predicates). The latter aspect is generally taken to distinguish between particular vs. generic readings of NPs. Givón $(1978,296)$ also makes clear that he understands definiteness as a property of linguistic discourse structure, rather than of the world: "The notions 'definite' and 'indefinite', as far as referential nominals are concerned, are used here strictly in their discourse-pragmatic sense, i.e. 'assumed by the speaker to be uniquely identifiable to the hearer' vs. 'not so assumed', respectively." However, the definition in terms of attitudes of the speaker towards the mental representation of the hearer is quite complex, making this definition quite difficult to work with. Therefore, the simplified picture (3) is generally used. Haspelmath $(1997,46)$ uses the categorization (6) for distinguishing different classes of indefinite pronouns: ${ }^{2}$

(6) (In-)definiteness, (non-)specificity and knowledge of the speaker (Haspelmath 1997)

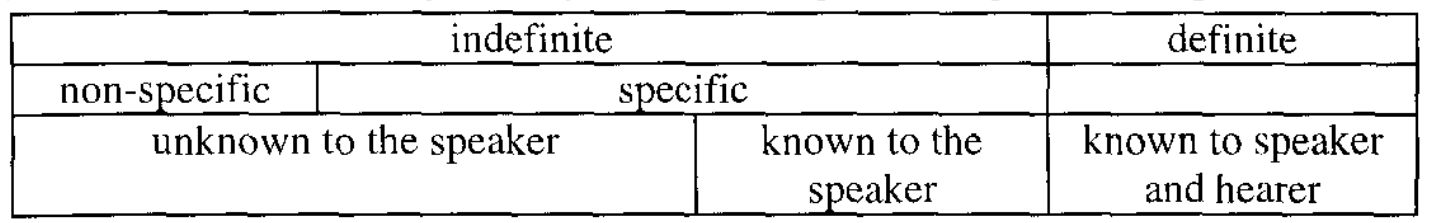

The categorization in (5) is also used in the discussion of Differential Object Marking (= DOM from German Differentielle Objektmarkierung, Bossong 1985). DOM is the cross-linguistically widespread phenomenon that describes the morphological marking of a subclass of direct objects. One example of this form of object marking is discussed in section 3 for Turkish. In general, DOM predicts that case marking (of the direct object) operates on a scale. Bossong $(1985,6)$ proposes the "Skala der Referenzmerkmale" ("scale of referential features"), as in (7). Aissen $(2000,7)$ builds this scale into a larger "Definiteness Scale" (8):

$$
\begin{aligned}
& \text { Skala der Referenzmerkmale (Bossong 1985) } \\
& {\left[\text { id } \mathrm{ego}^{\wedge}[\mathrm{id} \mathrm{tu}]>[\mathrm{id} \mathrm{ego} \wedge \text {-id tu }]>\left[-\mathrm{id} \mathrm{ego}^{\wedge}[-\mathrm{id} \mathrm{tu}]\right.\right.} \\
& \text { Definiteness Scale (or Hierarchy) (Aissen 2000) } \\
& \text { Pronoun }>\text { Name }>\text { Definite }>\text { Indefinite }>\text { NonSpecific }
\end{aligned}
$$

There are two tacit assumptions of this view on the relation between definiteness and specificity that I think are incorrect: (i) definiteness is explained in terms of identifiability of the referent, and (ii) specificity is a subcategorization of indefinite NPs (which means that there are no non-specific definite NPs). There is no convincing evidence for either of the claims; rather the research has given plan evidence for the contrary. Definiteness (and thus specificity) cannot be reduced to the concept of identification, as it is illustrated by the following examples. The definite NPs the righteous man and the doors in the two fragments (9) and (10) cannot be identified by the speaker and hearer, they do not even refer to identifiable objects, and in (10) the definite NPs do not even refer to any existent object. Example (9) nicely illustrates that the NP is definite because it is anaphorically linked to a discourse item already introduced (but not necessarily to an identified referent "in the world"). The indefinite

2 Haspelmath has the three-way distinction for indefinites: non-specific; specific + unknown to the speaker; and specific and known to the speaker. This seems to correspond to the English anyone, someone [non-specific], someone [specific]. 
NP a secret in (11) has a clear specific reading, but it cannot be identified by speaker or hearer (this is warranted by the plot of the story). On the other side, the two indefinite NPs one of my monks and an equally terrible $\sin$ in (12) have referents that are wellknown to both the speaker and the hearer (it is the dead monk Adelmo and the sin of homosexuality, respectively). In a theory of identifiability, one would expect definite NPs instead of the indefinites. This can only be explained in the view of discourse representation: the two referents cannot be linked to a discourse referent already established - that is why indefinite NPs are used.

(9) [...] And I know that he [= the Evil One] can impel his victims to do evil in such a way that the blame falls on a righteous man, and the Evil One rejoices then as the righteous man is burned in the place of his succubus. (29)

(10) William asked him whether he would be locking the doors.

"There are no doors that forbid access to the scriptorium from the kitchen and the refectory, or to the library from the scriptorium." (85)

(11) The fact is, Benno said, he had overheard a dialogue between Adelmo and Berengar in which Berengar, referring to a secret Adelmo was asking him to reveal, proposed a vile barter, which even the most innocent reader can imagine. (137)

(12) It would already be serious enough if one of my monks had stained his soul with the hateful sin of suicide. But I have reason to think that another of them has stained himself with an equally terrible sin. (33)

There is no convincing definition of definiteness (and specificity) in terms of identifiability. I will assume here that definiteness expresses the discourse pragmatic property of familiarity (Karttunen 1976, Heim 1982, Kamp 1981, and following work in discourse semantics). The second question is then what is the nature of specificity. I assume that specificity is a "referential property" of NPs. This property cuts across the distinction of definite vs. indefinite, like genericity. Prince $(1981,231)$ observes that both definite and indefinite NPs exhibit different "ways of referring": "3
a. A body was found in the river yesterday.
b. A tiger has stripes.
c. John is a plumber.
d. I never saw a two-headed man.
e. He won't say a word.

\footnotetext{
Prince (1981, 231: "In their most usual reading, only the italicized NP in ( $1 \mathrm{a})[=(13 \mathrm{a}), \mathrm{KvH}] \mathrm{can}$ actually be said to be specific. The italicized NPs in (lb-e) $[=(13 \mathrm{~b}-\mathrm{e}), \mathrm{KvH}]$ are all non-specific, though of different types (generic, predicative, attributive, and negative polarity idiom-piece, respectively). However, definite NPs exhibit a similar range of understandings". My use of "nonspecific" correlates to Prince's "attributive" since I assume that specific as well as non-specific NPs are "individualized", i.e. refer to one individual.
} 
(14) a. The body was found in the river yesterday.

specific

b. The tiger has stripes.

[= referential, $\mathrm{KvH}]$

c. $\quad$ Ronald is the president.

generic

d. They'll never find the man that will please them.

e. He doesn't mean the slightest thing to me.

predicative

attributive

[= non-specific, $\mathrm{KvH}]$ idiom piece

negative polarity

The exact nature of specificity will be discussed in section 6. Informally, specificity mirrors a more fine-grained structure of referential relations between the items used in the discourse (what Jackendoff 1972 calls "modal structure"). This structure is independent of the discourse pragmatic status of the NP (expressed in terms of definiteness) and the scopal behavior of that NP. Specificity affects definite NPs as well as indefinite NPs. A specific NP indicates that the associated discourse item is referentially anchored to another discourse item, and therefore, inherits the scopal properties of its anchor (among other properties). ${ }^{4}$

(15) Cross-classification of definiteness and specificity

\begin{tabular}{|l|l|l|}
\hline & discourse old & discourse new \\
\hline $\begin{array}{l}\text { referentially anchored to } \\
\text { discourse referents }\end{array}$ & $\begin{array}{l}\text { referential or specific } \\
\text { def. NPs }\end{array}$ & specific indef. NPs \\
\hline $\begin{array}{l}\text { referentially bound by } \\
\text { operators }\end{array}$ & $\begin{array}{l}\text { attributive or non- } \\
\text { spec. def. NPs }\end{array}$ & non-spec. indef. NPs \\
\hline
\end{tabular}

This picture is confirmed by the early literature on specificity where often a comparison was made between non-specific indefinite NPs and attributive readings of definite NPs, on the one hand, and specific indefinite NPs and referential definite NPs on the other. (cf. Partee 1970). However, the comparison was mainly explained in terms of scope or in terms of an ambiguity between quantifiers and a referential operator (see section 4.1 and 4.2)

\section{Grammatical encoding of specificity}

As opposed to definiteness, there are no sets of specific vs. non-specific articles in IndoEuropean languages. This probably caused the assumption of the purely pragmatic nature of specificity in contrast to the semantic nature of definiteness (see section 4.1). However, there are many other languages that mark specificity lexically or morphologically. Lyons $(1999,59)$ summarizes observations from other languages: "Articles marking specificity, or something close to specificity, rather than definiteness are fairly widespread." Specificity is also often mentioned with respect to DOM ("differentiated object marking", see above). Bossong (1985, viii) notes that there are

4 I assume that every NP receives an index that must be either anchored to a discourse item or bound by some discourse operator (such as negation, intensional verbs etc.). The second condition is necessary since both definitc and indefinite NPs are terms which can serve as antecedents for anaphoric pronouns. In an alternative view, indefinites are predicates that can receive a "singular term"-reading contextual force. However, in such a view there is no uniformity of definite and indefinite NPs. See section 6 for more discussion. 
more than 300 languages from all over the world that exhibit DOM. In the remainder of this section, I present data from Turkish where specificity is reflected in the morphological marking of the direct object (which is often subsumed under DOM) and of the subject in embedded sentences. ${ }^{5}$

\subsection{Turkish}

Turkish is an agglutinating and suffixing language. The main verb is sentence final and most suffixes are phrase-final. The unmarked word order is: subject $>$ indirect object $>$ direct object $>$ predicate, as illustrated in (16):
ressam biz-e resim-ler-i
göster-di
artist Ipl-dat picture-pl-acc
'An artist showed us picture'
show-di.past

Embedded clauses are realized by nominalized predicates. The subject of such nominalized predicates is in the genitive (with or without a genitive case ending - see below). The genitive shows agreement on the nominalized predicate in form of possessive suffix. Embedded sentence can be arguments of superordinated predicates, as illustrated in (17):

$$
\begin{aligned}
& \text { [Türkiye'nin }{ }_{1} \text { büyük ol-duğ-un }{ }_{1} \text {-u } \quad \text { bil-ir-im } \\
& \text { Turkey-gen big be-NOM-3pos]-acc know-aor-1sg } \\
& \text { 'I know the big-being of Turkey' = 'I know that Turkey is large' }
\end{aligned}
$$

\subsection{Turkish object marking}

A language specific implementation of specificity is found in Turkish (Kornfilt 1997, 219ff). Turkish does not have a definite article, but an indefinite article bir, which is derived from the numeral bir, but which differs in distribution. The direct object can be realized by the absolut(ive) without case endings or by the accusative with the case ending $-I$. Thus the definite reading of $a$ book is generally expressed by the accusative case ending, as in (18b), while the indefinite reading is realized by the indefinite article plus the absolutive, as in (18c). However, the combination of the markers for definiteness and indefiniteness in (18d) expresses an indefinite specific NP. (18a) expresses a reading that comes close to an incorporated one (see Lewis 1967, Dede 1986, Kornfilt 1997 among others)

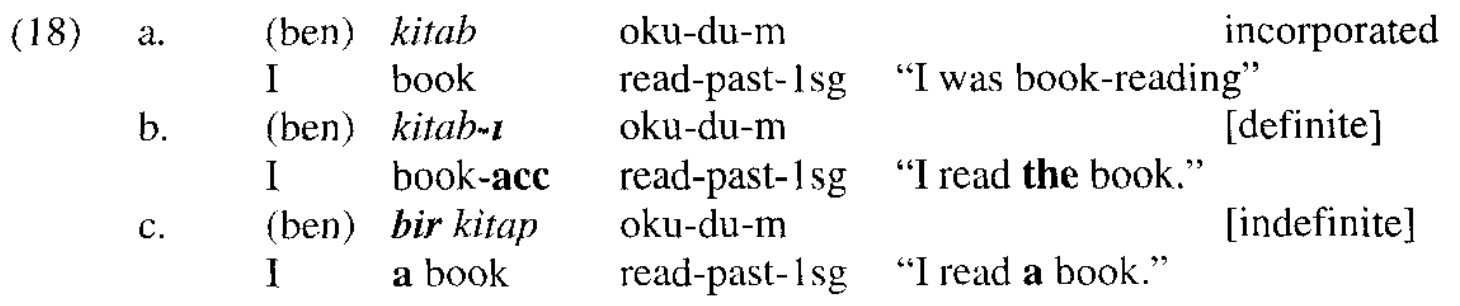

\footnotetext{
5 This observation goes back to Kornfilt (1997). I am not aware of other work that compares DOM with the marking of subjects in embedded sentence. Kornfilt (1997) assumes that the marking of specificity is not restricted to the direct object but also to the subject. However, this is only visible in embedded subjects since the subject of the matrix sentence never receives a case.
} 


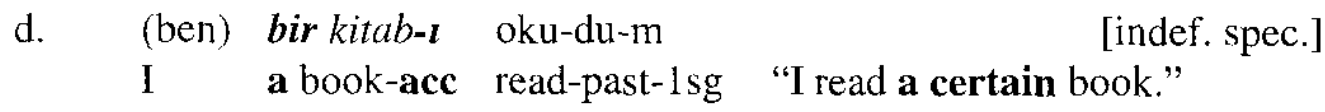

Direct objects with case endings can only receive a specific reading, as illustrated in (19a) and (19b) from Dede $(1986,158):^{6}$
a. Bir öğrenci arı-yor-um.
Bulan-m1-yor-um
a student look_for-prog-1sg find-NEG-aor-1sg
'I am looking for a student. I can't find him'
[specific]
'I am looking for a student. I can't find one'
[non-specific]
b. Bir öğrenci-yi arı-yor-um. Bulanmyorum
a student-acc look_for-prog-1sg find-NEG-aor-1sg
'I am looking for a student. I can't find him'
[specific]

(*I can't find one)

[non-specific]

\subsection{Turkish subject marking}

A similar contrast exists for the subject of embedded sentences. The predicate of an embedded sentence in Turkish is a nominalized form that shows agreement with the subject, realized by the possessive marker $-I$. The subject is realized in the genitive, either with the case ending $-I n$, or without the combination of the indefinite article bir and the genitive case marks a specific subject (Kornfilt 1997, 219ff, ex. (762)=(20a)). Note that the non-specific subject tends to be closer to the predicate, while the specific one appears more clause-initial.
a. [köy-ü haydut
[village-acc robber
bas-tığ-1n]-1 duy-du-m
"I heard that robbers raided the village"
b. [bir haydut-un köy-ü bas-tı̆
[a robber-gen village-acc raid-Nom-poss. $3 \mathrm{sg}$ ]-acc hear-Past-1sg
"I heard that a certain robber raided the village"

\subsection{A contrastive view}

Even though the data are more complex than the given picture (see footnote 7), I assume that the case marking of the direct object and of the embedded subject in combination with the indefinite article is a fairly good indicator of a specific indefinite NP. This test

6 Dede $(1986,157)$ observes that the condition for case marking of the direct object are more complex. Among other conditions, movement is marked by the case: "The direct object which is removed from its unmarked position, that is, from immediately preverbal position for some reason such as focusing or contrast of another constituent always takes the ACC case endings."
(i)
Bizim ev-de çay-1 her zaman
our house-loc
tea-acc always
Aytül
yap-ar
'Aytül always makes the tea in our family'
(ib) *Bizim ev-de çay her zaman Aytül yap-ar

Johanson (1977, cited from Johanson 1990, 181) had already observed this: „In dem Beitrag Johanson $(1977, \ldots)$ wird geltend gemacht, daß die vom Akkusativsuffix getragene Idee der ,Spezifizität nur in der Position unmittelbar vor dem regierenden Verb systematisch realisiert werden könne und daß der Akkusativ sonst meist als reiner Objektindikator funktioniere." Therefor, I use only examples with the direct object in its base position. 
is in any case more robust than the more indirect indicators in English or Italian, illustrated by the translation in (21). The context of the novel is that one monk indicates to William of Baskerville (the medieval Sherlock Holmes) that he knows something (specific!), but that he is not ready to disclose it: "[...] But in the abbey there are rumors, ... strange rumors ..." - "Of what sort?"

(21) a. i "Strane. Diciamo, di un monaco che nottetempo ha voluto avventurarsi in

ii biblioteca, per cercare qualcosa che Malachia non aveva voluto dargli, e ha

iii visto serpenti, uomini senza testa, e uomini con due teste. Per poco non

iv usciva pazzo dal labirinto ..."

b. i "Strange. Let us say, rumors about a monk who decided to venture into the ii library during the night, to look for something Malachi had refused to give

iii him, and he saw serpents, headless men, and men with two heads. He was

iv nearly crazy when he emerged from the labyrinth ..."

c. i Garip söylenti-ler örneğin, [bir rahib-in geceyarısı, [[Malachi'nin $_{2}$ kendine strange rumor-pl for example, [a monk-gen midnight [[M.-gen himself-dat

ii ver-mek iste-me-diğ-i ${ }_{2}$ bir kitab-ı bul-mak için] gizlice give-inf want-NEG-NOM-poss.3sg] a book-acc find-inf to ] secretly

iii kitaphığ-a girmey-e kalkış-tığ - 11$]_{1}$ (..) dair söylenti-ler library-dat enter-to venture-NOM-poss.3sg] about rumor-PI 'There are strange rumors, for example rumors about [a monk midnights secretly into the library venturing [to find a book [that Malachi did not want to give him]]]'

The context of the novel strongly suggests that the speaker knows the referent of the indefinite NP a monk/un monaco but not the referent of the indefinite pronoun something/qualcoso. The specificity of the indefinite a monk is indicated in different ways: In the English translation the anaphoric pronoun he in (2lbiii) doesn't seem to be embedded under the NP rumors. If that is the case then the indefinite NP a monk must be specific, otherwise it could not serve as antecedent for the pronoun. In the Italian original the indicative mood of the relative clause ( $h a$ voluto) indicates that the head noun un monaco is specific. This is confirmed by the Turkish translation, where the subject bir rahib-in of the embedded sentence that ends in kalkihtıgl shows double marking (indefinite article plus case ending).

Note that the Turkish translation bir kitabl for the Italian qualcosa or English something in line (ii) is marked as specific. The specificity of this NP is confirmed by the setting of the novel (and the lexical meaning of the word involved): Malachi (the librarian) can only refuse to give something to the monk if the monk had asked for a specific thing. In Italian, the predicate aveva voluto in the relative clause is in the indicative, and thus indicating that the head noun qualcosa is specific. In English, the relative clause modifying something contains the proper name Malachi, which again is a good indication that the indefinite pronouns is linked to the referent of that proper name. In comparing the three languages, Turkish marks specificity clearly, whereas subtle indicators in English or Italian must be looked for. 


\subsection{Unsolved cases}

Specificity is marked in Turkish by the combination of case suffixes and the indefinite article. However, a close inspection of all those cases where we find case marking and the indefinite article reveals that we cannot always account for this marking in terms of specificity defined as "the speaker has in mind" or as wide scope of the indefinite. This was already the case in (21) with something/qualcose/bir kitabr. The following two cases are similar: the indefinite NP bir kitabt in (22b) cannot be known to the speaker (that would contradict the plot of the story) but is still marked a specific. The NP in (23) is embedded under the conditional expressed by the conditional suffix -se. It would not make sense to give wide scope to the indefinite or give it a referential reading, still it is marked as specific.

(22) a. The day before, Benno had said he would be prepared to $\sin$ in order to procure a rare book. He was not lying and not joking. (183)

b. Bir gün önce Benno az bul-un-ur bir kitabı elde etmek için

One day before B. rare find-pass-SP a book-acc procure-inf to

seve seve günah işleye-ceğ-in-i söyle-mişti.

with pleasure sin commit-fut-3sg-acc say-mih.past.

Yalan söyle-mi-yor-du; haka da yap-m1-yor-du. (261)

lie say-NEG-prog-di.past; joke also make-NEG-prog-di.past

$\begin{array}{llll}\text { Bir rahip } \quad \text { bir kitab-1 almak } & \text { iste-r-se, } & (\ldots) \\ \text { a monk a book-acc take } & \text { want-Aor-Cond } & (\ldots) \\ \text { 'If a monk wants to take a book }(\ldots)\end{array}$

These examples can, of course, be understood as showing that the combination of case suffix and indefinite article doesn't always indicate specificity. However, as long as we do not know what kind of phenomena we are ready to subsume under the term specificity we cannot resolve this problem.

\section{Types of specificity}

In the discussion of specificity, different kinds of specific indefinites are distinguished. The main distinction is organized into two dimensions: scope and referentiality. A prototypical specific indefinite is assumed to have wide scope and a referential reading. Depending on the theory, the one or other aspect is more focused upon. Following Farkas (1995), I present the following groups: (i) scopal specific indefinites, (ii) epistemic specific indefinite, and (iii) partitive specific indefinite. I discuss an additional group (iv) which I call "relative specific indefinites".

\subsection{Scopal specificity}

Classically, the contrast between a specific and a non-specific reading of an indefinite is illustrated by examples such as (24). The historical reason for this is that in the same context definite NPs show different readings (see (3) and (4) above). ${ }^{7}$ The paraphrases

\footnotetext{
It is interesting to note that many people who illustrate specificity with this example deny that it is also a catcgory for definite NPs (sce the discussion in section 2).
} 
in (24a) and (24b) motivate the specific and non-specific readings in term of scope, respectively. (24a) can be continued with the (24a') since the pronoun her refers back to the existential quantifier that is outside of the scope of want. In (24b), the quantifier is inside the scope, thus a link to a pronoun is not possible. Therefore, we can only continue as in (24b'):

(24) John wants to marry a Norwegian.

a. There is a Norwegian , and John wants to marry her $_{1}$.

a'. He met her! last year.

b. John wants that there is a Norwegian 1 and he marries her ${ }_{1}$.

b'. He will move to Norway to try to achieve this goal.

The interaction of the indefinite with other operators can also be illustrated with negation, as in (25), with a universal quantifier, as in (26), or it can interact with more than one other operator, as in (26) and (27). In these cases we expect three readings, which the reader can easily work out.

(25) Bill didn't see a misprint.

(Karttunen 1976)

a. There is a misprint which Bill didn't see.

b. Bill saw no misprints.

Bill intends to visit a museum every day.

(Karttunen 1976)

Luce expects Pinch to ask him for a book.

(Kasher \& Gabbay 1976)

Karttunen $(1976,377)$ observes that we can disambiguate a sentence with an indefinite and another operator by anaphoric linkage. While the indefinite NP in (28) can be specific or non-specific, it can only be specific in (29).

(28) Harvey courts a girl at every convention.

(29) Harvey courts a girl at every convention. She is pretty

\subsection{Epistemic specificity}

The contrast described in the last section arises in the presence of other operators such as negation, universal quantifier or verbs of propositional attitudes. An analysis in terms of scope seems to work well. However, there are examples that show the same (intuitive) contrast, but do not contain other operators. In the specific reading of (30), we can continue with (30a), while the non-specific reading can be continued by (30b). Kasher \& Gabbay (1976) mention examples (31)-(33), where they state a clear contrast between a specific and a non-specific reading. This contrast is also often described as referential vs. non-referential terms. The specific indefinite refers to its referent directly, while the non-specific indefinite depends on the interpretation of other expressions in the context.

8 There are exceptions to this rule, if the continuation includes a similar quantifier as the antecedent sentence:

(i) Harvey courts a girl at every convention. She always comes to the banquet with him. 
(30) A student in Syntax 1 cheated on the exam

(Fodor \& Sag 1982)

a. His name is John

b. We are all trying to figure out who it was

(31) I talked with a magician and so did Uri.

(Kasher \& Gabbay 1976)

(32) Olivia is married to a Swede, but she denies it.

(33) A book is missing from my library.

\subsection{Partitive specificity}

Milsark (1974) argues that indefinite NPs can either receive a weak (or existential) interpretation or a strong (or prepositional) interpretation. In (34) the indefinite some ghost receives a weak interpretation, but gets a strong interpretation in (35) (presupposing that there are other groups of ghosts.) The reading in (35) is generally called "partitive".

\section{(34) There are some ghosts in this house}

(35) Some ghosts live in the pantry; others live in the kitchen

Enç (1991, 5f) observes that this contrast between a partitive and a non-partitive reading of indefinite NPs is in the same way morphologically marked as the contrast between specific vs. non-specific indefinite (see section 3 above for the details of Turkish). Given (36) as the background knowledge for the participants, the speaker can utter (36a) expressing the partitive meaning: the two girls must be included in the named set. In Turkish this is marked by the accusative suffix $-i$ on the direct object. Continuing with (36b) (without the suffix), the two girls are not included in the mentioned set. (36a) is equivalent to (37) with an overt partitive:

Oda-m-a birkaç çocuk gir-di

room-poss.1sg-dat several child enter-di.past

'Several children entered my room'
a. Iki k1z-1 tant-yor-du-m
two girl-acc know-prog-di.past-1sg
'I knew two (of the) girls'
b. Iki k1z an1-yor-du-m
two girl know-prog-di.past-1sg
'I knew two girls'
[partitive]
[non-partitive]
Kiz-lar-dan iki-sin-i
tan1-yor-dum
girl-pl-abl two-pass.3sg-acc know-prog-di.past-1sg

[overt partitive construction]

'I knew two of the girls'

Enç claims that partitives denote an unknown subset of a given set, here, two girls from the set of given girls. Partitives always exhibit wide scope since the set from which they pick some elements out is already mentioned. This means that partitives are complex expressions that are formed by an indefinite choice from a definite set. This view is 
supported by the contrast between the following three partitive expressions from the novel The Name of the Rose: the partitive one of my monks in (38) has a specific reading - it refers to the monk Adelmo, who has been found dead at the beginning of the story. In (39), the partitive is rather non-specific, while in (40), it is a negative one.

(38) "It would already be serious enough if one of my monks had stained his soul with the hateful sin of suicide. But I have reason to think that another of them has stained himself with an equally terrible sin." (33)

(39) "In the first place, why one of the monks? In the abbey there are many other persons, grooms, goatherds, servants..." (33)

(40) The library was laid out on a plan which has remained obscure to all over the centuries, and which none of the monks is called upon to know. (37)

So it seems that partitives are rather formed by two independent referential functions: the first can be specific, non-specific, negative, etc., while the second must be definite. I therefore, do not include them in the investigation of specific indefinites proper.

\subsection{Relative specificity}

There are indefinite NPs that are neither wide scope nor referential, but are still "specific". Higginbotham $(1987,64)$ illustrates this by the examples $(41)$ and $(42)$ :

"In typical cases specific uses are said to involve a referent that the speaker "has in mind.' But this condition seems much too strong. Suppose my friend George says to me, 'I met with a certain student of mine today.' Then I can report the encounter to a third party by saying, 'George said that he met with a certain student of his today,' and the 'specificity' effect is felt, although I am in no position to say which student George met with."

(41) George: "I met a certain student of mine"

(42) James: "George met a certain student of his."

Hintikka (1986) had made a similar observation in his discussion of the expression $a$ certain. In (43), he shows that the specific indefinite a certain woman can receive narrow scope with respect to the universal quantifier and still be specific: there is a specific woman for each man. Hintikka suggests that the specific indefinite NP is to be represented by a Skolem-function that assigns to each man the woman who is his mother. With Farkas (1997) we can describe the dependency of the specific NP a certain woman from the universal quantifier every man by the concept of "co-variation:" Farkas builds this dependency into the interpretation process: The value for the specific indefinite woman co-varies with the value for man. In other words, once the reference for man is fixed (during the process of interpreting the universal quantifier), the reference for the specific indefinite is simultaneously fixed. In (43b), I informally

9 Lyons $(1999,100)$ expresses a similar view with respect to the partitive article in French: "The partitive article is almost certainly best regarded as a genuine partitive construction, and not as an indefinite article." 
indicate this by indexing the indefinite NP with the variable bound by the universal quantifier. ${ }^{10}$

(43) According to Freud, every man unconsciously wants to marry a certain

woman - his mother. (Hintikka 1986)

a. $\quad \forall x[\operatorname{Man}(\mathrm{x})->\operatorname{Wants}(\mathrm{x}, \operatorname{marry}(\mathrm{x}, \mathrm{f}(\mathrm{x}))]$

with $\mathrm{f}$ : Skolem function from men into their mothers

b. $\quad \forall x\left[\operatorname{Man}(\mathrm{x}) \rightarrow \operatorname{Wants}\left(\mathrm{x}, \operatorname{marry}\left(\mathrm{x},[\mathrm{a} \text { woman }]_{\mathrm{x}}\right]\right.\right.$

These observations motivate a revision of the pre-theoretical description of specificity as the "certainty of the speaker about the referent". It was shown that a specific indefinite NP need not depend on the speaker or the context of utterance, it can also depend on other linguistic entities like the universal quantifier every man in (43) or on the proper name George in (42). This was the same dependency we have informally stated in (1), where the indefinite pronoun something depends on the indefinite NP $a$ monk. In the following sections, I assume that specificity is a marker for an expression that is referentially anchored to another expression, rather than "absolutely" related to the speaker. Before I give my formal reconstruction of this idea, I present some current approaches to specificity.

\section{Semantic theories of specificity}

In the following I discuss three semantic approaches to definiteness and specificity: (i) the pragmatic view; (ii) the lexical ambiguity view, and (iii) the discourse semantics approach. The first two theories share the assumptions that definite and indefinite NPs are both quantifier phrases. The difference between the quantifier phrases is the uniqueness condition of the definite article. The theories differ in the conception of specificity: the pragmatic approach explains scopal specificity in terms of scope behavior of the quantifiers involved, while epistemic specificity is seen as a purely pragmatic notion. The lexical ambiguity view assumes that there are two interpretations of indefinite NPs: an existential and a referential. The latter has the same properties as other referential terms such as proper names and deictic expressions. Discourse semantics, on the other hand, perceives the difference between definite and indefinite NPs not in the uniqueness condition but in the discourse-pragmatic familiarity condition. A definite expression is linked to an already introduced discourse item, while a indefinite NP is not. Specificity is primarily treated as an irregular behavior of indefinites - indefinites that can introduce their discourse referents in any of the superordinated boxes.

All three approaches in their classical versions are unable to account for relative specific indefinites. However, there are extensions of each of the mentioned approaches that are intended to cover exactly these cases: Schwarzschild (2000) and Yeom 1997 suggest domain restrictions for the pragmatic approach, Kratzer (1998) proposes

10 Farkas focuses on a somewhat different case, namely on indefinites in the scope of some operator. She describes then the narrow scope (= "non-specific") indefinites as "dependent indefinite". Thus, according to Farkas, dependent indefinites are non-specific. In my view, they can be specific if they co-vary with the value of an extensional operator like in (43) (see section 6 below). 
dependent choice functions for the referential reading of the indefinite article; Geurts (2001) proposes accommodation for discourse semantics approach.

\subsection{Quantifiers and pragmatics $I$}

The classical theory of NPs (Frege, Russell, Montague) translates definite and indefinite NPs into quantifiers: indefinite NPs are existential quantifier phrases, while definite NPs are translated into a complex quantifier phrase expressing uniqueness of the object that falls under the description. Thus, the difference between indefinite and definite NPs is semantically expressed in the uniqueness condition. This was the background of this classical theory, as the notion of specificity was introduced in the late $60 \mathrm{~s}$. When the de re-de dicto ambiguity of definite NPs was applied to indefinite NPs, a similar contrast appeared in the context of verbs of propositional attitudes, negation, questions, conditionals, modals, future, and intensional verbs (see Jackendoff 1972). I illustrate this on the interaction from negation and NPs in (44)-(47):

(44) William didn't see the book - until he saw it in the finis africae.

$$
\text { a. } \quad \forall \mathrm{x} \exists \mathrm{y}[\operatorname{book}(\mathrm{y})->\mathrm{x}=\mathrm{y} \& \neg \operatorname{See}(\text { william, } \mathrm{x})]
$$

(45) William didn't see the book - he began to wonder if there is one.

$$
\text { a. } \quad \neg \forall \mathrm{x} \exists \mathrm{y}[\operatorname{book}(\mathrm{y})->\mathrm{x}=\mathrm{y} \& \operatorname{See}(\text { william, } \mathrm{x})]
$$

(46) William didn't see a book from the finis africae - until he saw it in the hands of Jorge de Burgos.

a. $\quad \exists y[\operatorname{book}(y) \& \neg \operatorname{See}($ william, $x)]$

(47) William didn't see a book - so he knew that they had removed all books.

a. $\quad \neg \exists y[\operatorname{book}(y) \operatorname{See}(w i l l i a m, x)]$

Epistemic specificity, as in (48), is explained by pragmatic principles. The characterization of specific NPs as "the speaker as the referent in mind" is of purely pragmatic grounds - in the course of discourse, the speaker and hearer might get sufficient descriptive material in order to be able to uniquely identify the indefinite NP (cf. Neale 1990, Ludlow \& Neale 1991).

A book is missing from my library.

This view was disputed by Jackendoff (1972) and Fodor (1970). They argued that specificity cannot be explained in terms of quantifier scope - there must be an additional structure, what Jackendoff calls "modal structure". However, they had not the appropriate means to describe this structure in an adequate way.

\subsection{Lexical ambiguity approach}

Fodor \& Sag (1982) propose a lexical ambiguity of the indefinite article, giving up a uniform analysis of indefinites. Indefinites have either a specific or referential reading or they have a non-specific or existential reading. They assume that the contrast between the two readings is incommensurable. They illustrate this point by the interaction of indefinites with quantifiers as in (49). The indefinite has either a specific reading or a non-specific reading. The classical approach to this contrast is by means of different 
scope: the indefinite NP can get wide or narrow scope with respect to the definite NP the rumor, reflecting the specific and non-specific reading, respectively. However, the universal phrase each student in (50) cannot receive wide scope due to an island constraint. Thus, the specific reading in (49) cannot be described by a wide scope existential quantifier. Fodor \& Sag propose that the indefinite NP is either interpreted as a referring expression or as an existential quantifier. The referring expression is scopeless like proper names and demonstratives, i.e. it behaves as if it always had widest scope, as in (49b). The quantificational interpretation, as in (49a), must observe island constraint like other quantifiers and accounts here for the non-specific reading.

(49) John overheard the rumor that a student of mine had been called before the dean.
a. the rumor $>$ there is a student
b. a certain student.$>$ the rumor ... he ...

(50) John overheard the rumor that each student of mine had been called before the dean.
a. the rumor $>$ each student
b. $\quad$ *each student $>$ the rumor

The theory makes a clear prediction: an indefinite is interpreted either as a referential term and always receives widest scope, or as an existential quantifier, which has to obey scope islands. We can now test this prediction on examples with two quantifiers as in (49) or (51). In both sentences, there are two quantifiers beside the indefinite, which stands in a scope island. According to Fodor \& Sag's theory, we would only expect a narrow scope reading by the existential interpretation and a wide scope reading by the referential interpretation, but no intermediate reading. While judgements on intermediate readings are quite intricate, Farkas (1981) observed on examples, like (51), that intermediate readings are often very natural. (51) has a reading according to which for each student there is one condition such that the student comes up with three arguments against the condition.

(51) Each student has to come up with three arguments that show that some condition proposed by Chomsky is wrong.

a. each student $>$ some condition $>$ three arguments ...

The intermediate reading (52a) of (52) clearly states that even such a radical theory of ambiguity cannot exhaustively describe the flexibility of indefinite NPs.

Kratzer (1998) defends the lexical ambiguity hypothesis of Fodor \& Sag (1982). She assumes that an indefinite NP is either represented as an existential quantifier, which obeys island constraints, or as a choice function $f$, which is bound by the context and, therefore, has widest scope. A choice function $f$ or $\Phi$ is a function that assigns to a set one of its elements. In other words a choice function "selects" one element out of the set that is expressed by the descriptive material. Following von Heusinger $(1997,2000)$ I represent indefinite NPs as indexed epsilon terms, as illustrated in (52). The reason for this is to distinguish between the logical representation (epsilon terms) and the semantic interpretation (choice functions). The epsilon operator is interpreted as a choice function 
that assigns one element to each set. ${ }^{11}$ In other words, the referent of an indefinite NP is found by selecting one element out of the set that is described by the description. Kratzer assumes that the choice function is always anchored in the context of utterance, here indicated with speaker. However, the intermediate reading is created by the dependence of descriptive content of the indefinite from the value for professor. The extension of the set of books recommended by $\mathrm{x}$ co-varies with the value of $\mathrm{x}$ for professor. The choice function picks different elements from different sets. Note that the set of recommended books can contain more than one book. It is the choice function that singles out one element:

$$
\begin{aligned}
& \text { a condition: } \varepsilon_{\mathrm{i}} \mathrm{x}[\text { condition }(\mathrm{x})] \\
& \text { a. } \quad\left[\left[\varepsilon_{\mathrm{i}} \mathrm{x}[\text { condition }(\mathrm{x})]\right]\right]=\Phi([[\text { condition }]]) \\
& \text { b. } \quad \Phi([[\text { condition }]]) \in([[\text { condition }]])
\end{aligned}
$$

(53) Every professor rewarded every student who read a book he had recommended.

$$
\begin{array}{ll}
\text { a. } & \forall x\left[\operatorname { p r o f } ( x ) \rightarrow \forall y \left[\operatorname{stud}(y) \& \operatorname{read}\left(y, \varepsilon_{\text {speaker }} \mathrm{z}[\operatorname{book}(\mathrm{z}) \& \operatorname{rec}(\mathrm{x}, \mathrm{z})]\right) \rightarrow\right.\right. \\
& \operatorname{rew}(\mathrm{x}, \mathrm{y})]] \\
\text { b. } \quad & \left.\| \text { a book he had } \operatorname{recommended} \|=\varepsilon_{\text {speaker }} \mathrm{z}[\operatorname{book}(\mathrm{z}) \& \operatorname{rec}(\mathrm{x}, \mathrm{z})]\right)
\end{array}
$$

There are two problems with this account (cf. the discussion in Winter 1997 and von Stechow 2000). First, Farkas (1981) showed with examples like (51) that intermediate readings are possible even without variables in the indefinite NP. This problem can be accommodated if one assumes that additional material can be copied into the description of the indefinite NP (here: some condition $x$ finds difficult). Second, if the set described by the descriptive material of the indefinite is extensionally equivalent for two different choices of professors in (54a), the representation counter-intuitively predicts that they invite the same lady. Kratzer (1998), therefore, modifies her approach and indexes the choice function (here the epsilon operator) with the variable $x$ that is bound by the universal quantifier. She now can predict that depending on the professor $\mathrm{x}$, the choice from extensional similar sets can be different.

$$
\begin{aligned}
& \text { Every professor invited a lady he knew } \\
& \text { a. } \left.\quad \forall x\left[\operatorname{prof}(\mathrm{x}) \rightarrow \operatorname{invite}\left(\mathrm{x}, \varepsilon_{\text {speaker }}[\operatorname{lady}(\mathrm{y}) \& \operatorname{know}(\mathrm{x}, \mathrm{y})]\right)\right)\right] \\
& \text { b. } \left.\quad \forall \mathrm{x}\left[\operatorname{prof}(\mathrm{x}) \rightarrow \operatorname{invite}\left(\mathrm{x}, \varepsilon_{\mathrm{x}} \mathrm{y}[\operatorname{lady}(\mathrm{y}) \& \operatorname{know}(\mathrm{x}, \mathrm{y})]\right)\right)\right]
\end{aligned}
$$

\subsection{Quantifiers and pragmatics II}

An alternative way to handle the mentioned problems is taken by Schwarzschild (2000) who keeps to the classical picture described in section 5.1. He investigates the properties of unique indefinite NPs or "singleton indefinites", such as in (55).

$$
\text { Everyone at the party voted to watch a movie that Phil said his favorite. }
$$

11 Choice functions have recently become a fashionable tool for representing indefinites (cf. Kratzer 1998, Winter 1997, von Stechow 2000, von Heusinger 2000 among others). We use the epsilon operator as the syntactic representation of the indefinite article, while the choice function is the corresponding semantic function. 
Schwarzschild argues that the wide scope reading of the indefinite NP in (55) derives from the fact that its descriptive material uniquely describes one object. He then claims that all "referential indefinites" (or "specific indefinites") are singleton indefinites. In other words, it is just the descriptive material that causes the "feeling" of different scopes. He has to assume additionally implicit quantifier domain restrictions something that is necessary for other quantifiers, anyway. A restriction can also include variables that are bound by other quantifiers in the sentence. He uses this mechanism to account for the intermediate reading (56a) of sentence (56). By domain restriction with the additional material that they have worked on most extensively the indefinite uniquely describes a problem for each or the linguists (assuming all of them are working on at least one problem). Thus the indefinite some problem behaves as having wider scope than every analysis It is interesting to note that the same mechanism of adding a variable to descriptive material of the indefinite is used to "widen" the scope (Schwarzschild) and to make the scope more narrow (Kratzer above). Schwarzschild is able to explain the different scope "behavior" of the indefinite NP by assuming different domain restrictions on the indefinite that can stay in situ: none for the narrow scope reading, a restriction with a variable bound by most linguists for the intermediate reading, and a restriction somehow connected to the speaker or to more encyclopedic knowledge.

(56) Most linguists have looked at every analysis that solves some problem.

a. Most linguists - some problem - every analysis

(56') Most linguists have looked at every analysis that solves some problem that they have worked on most extensively
b. Most linguists...every analysis ... some problem $\emptyset$
c. Most linguists ... every analysis ... some problem that
they have worked on most extensively
intermediate
d. Most linguists ... every analysis ... some
problem that I find most difficult
that Chomsky had announced that it is solve

narrow scope

wide scope

I cannot evaluate this approach in detail, but I would like to hint at some problems: (i) the domain restriction always ends up with a uniquely identifying description - a simple domain restriction like that they like would not do. It is not so clear why we need singletons in examples like (51) above. Furthermore, the uniqueness condition for indefinites seems to be even more disastrous than for definites. Lewis (1979), Heim (1982), Reimers (1992) among others have convincingly shown that domain restriction to uniques is not always possible for definite NPs. Second, it is not clear what the difference between a definite NP and an indefinite NPs is if not uniqueness in the classical picture. Schwarzschild would answer that it is familiarity from the discourse representation theory, yet it is not clear what the theoretical framework is after all.

A related approach is proposed by Yeom $(1998,71)$, who models the "generally accepted intuition of specificity is that the speaker has something in mind." He extends the semantics of indefinites as existential quantifiers by an additional two place relation hccw for has cognitive contact with. One place is filled by the variable bound by the existential quantifier and the other must be salient in the local environment (e.g. the speaker or the subject of the sentence). The adjective a certain in English is the overt 
expression for this relation, however, specific indefinites without a certain do also express this relation. Thus, he can account for cases of relative specificity (see 4.4 above) in the following way $(1998,73)$. Sentence (57) has two readings: in reading (57a), there is one woman such that every Englishmen adores her - here the cognitive contact is licensed by the speaker. In the second reading, every Englishman adores a certain woman - his mother (everyone potentially a different woman). Here the cognitive contact is licensed by the variable $\mathrm{x}$ for Englishman. Thus, woman co-varies with Englishman.

Every true Englishman adores a certain woman - his mother.

a. $\forall x[\operatorname{true}$ Englishman $(\mathrm{x})->\exists y[\operatorname{woman}(\mathrm{y}) \& \operatorname{hccw}(\mathrm{x}, \mathrm{y}) \& \operatorname{adores}(\mathrm{x}, \mathrm{y})]]$

b. $\quad \forall x[$ true Englishman(x) -> $\exists y[w o m a n(y) \&$ hccw(speaker,y) \& $\operatorname{adores}(\mathrm{x}, \mathrm{y})]]$

Note that it is the same strategy as employed by Kratzer and Schwarzschild: inserting a variable into the descriptive material of the indefinite, the extension of the descriptive material co-varies with the value for the variable. However, in Yeom's approach, there is no restriction on the set that fulfills the descriptions - there could be different woman an Englishman adores. Therefore, the existential quantification looks more like a partitive construction, discussed in section 4.3 (one of the woman he has cognitive contact with). Remember, Kratzer prevents such problems by using choice functions and Schwarzschild by assuming a uniquely identifying description. If we modify Yeom's approach towards Schwarzschild's, all the problems discussed with Schwarzschild arise: (i) uniqueness is already problematic for definite NPs, (ii) if specific indefinites are also uniques, what is the difference from definite NPs then?

\subsection{Discourse representation}

Discourse representation theories (Karttunen 1976, Heim 1982, Kamp 1981) assume that NPs are represented as discourse referents associated with their descriptive material (or: as variables that are associated with sentences). So NPs do not refer directly to individuals but to discourse referents. The distinction between definite and indefinite NPs is that of familiarity: a definite expression receives a discourse referent that is linked to an already established discourse referent, while an indefinite receives a discourse referent that is not or cannot linked. Discourse referents of indefinite NPs are always inserted into the current discourse domain or box while referential terms introduce their discourse referents in the main box.

Kamp \& Reyle $(1993,290)$ assume with Fodor \& Sag that specific indefinite NPs are referring terms like proper names "Specifically used indefinites act as referring terms, terms that are used to refer to particular things, whose identity is fixed independently of the context in which the term occurs." Intermediate readings are represented by placing the discourse referent for the indefinite NP into some higher box - the exact rules for this are not given. They neither state conditions that restrict this assumed flexibility.

Geurts (2001) explains specificity in terms of backgrounding. He assumes that "Background material tends to float up towards the main DRS." Indefinite NPs are not ambiguous between a specific and non-specific reading; they always introduce variables and associated predicates. The predicates are inserted into the discourse structure according to their background status. This seems like another version of the scope theory discussed above, even though the predictions are somewhat different. 
To summarize, there have been basically two ways to model relative specific indefinites: In the pragmatic approach, domain restriction is used to produce a singleton set corresponding to the indefinite NP. In the lexical ambiguity view, choice functions are replacing a referential operator and they can depend on other linguistic expressions. Choice function naturally give one individual to each set. However, here a lexical ambiguity between specific and non-specific NPs are assumed. In the next section, I preset a unified approach.

\section{Specificity as referential anchoring}

The main assumption of my proposal is that indefinite NPs are translated into indexed epsilon terms. The index on the epsilon term is free. It can either be bound by operators like negation or the textual closure resulting in a non-specific reading, or it can be anchored to another discourse item such as the speaker or the subject of the sentence. In the following, I give a brief sketch of my model.

Following von Heusinger $(1997,2000)$ we represent indefinite NPs as indexed epsilon terms, as illustrated in (58):

$$
\text { a book: } \varepsilon_{\mathrm{i}} x[\operatorname{book}(\mathrm{x})]
$$

The epsilon operator is interpreted as a choice function that assigns one element to each set (see above (52)-(53)). In other words, the referent of an indefinite NP is found by the operation of selecting one element out of the set that is described by the description. The selection depends on the context in which the indefinite is located. This treatment is similar to that of discourse representation theories (Heim 1982; Kamp 1981), where indefinites introduce new individual variables or discourse referents. One of the main advantages of using choice function variables instead is the following: Indefinites need not be moved or raised for expressing different dependencies.

This approach differs from other approaches using choice functions (Winter 1997, Kratzer 1998) in at least two respects. Winter (1997) assumes that the choice function is existentially bound at some level. He would only describe specific indefinite NPs by scope interactions, anything else is pragmatics. Thus he stands in the pragmatic approach to specificity (see section 5.1). Kratzer, on the other side, assumes two different representations of indefinite NPs: either as choice functions (specific reading) or as existential quantifiers (non-specific reading). I assume that there is one representation of indefinites, namely as indexed epsilon terms. The index, however, may either be bound by some operator such as negation or existential closure, or it can be anchored to some discourse item. So we can analyze the readings of (59) as the nonspecific reading (59a), and the two specific readings (59b) and (59c). In (59a) the index is bound by an existential quantifier in the scope of the negation - therefore, the indefinite has narrow scope with respect to the negation. In (59b) and (59c), the index is anchored to the speaker and to the subject of the sentence, respectively. In both cases the indefinite receives wide scope with respect to the negation.

(59) William didn't see a book.

$$
\begin{array}{ll}
\text { a. } & \neg \text { i } \operatorname{See}\left(\text { william, } \varepsilon_{\mathrm{i}} \mathrm{x}[\operatorname{book}(\mathrm{x})]\right) \\
\text { b. } & \neg \operatorname{See}\left(w i l l i a m, \varepsilon_{\text {speaker }}[\operatorname{book}(\mathrm{x})]\right)
\end{array}
$$


c. $\quad \neg$ See(william, $\left.\left.\varepsilon_{\text {william }} \mathrm{x}[\operatorname{book}(\mathrm{x})]\right)\right)$

There is no difference between (59b) and (59c) in terms of scope. However, if we replace the subject with a quantifier phrase as in (43), repeated as (60), we get a different picture. (60a) is the representation for the relative specific reading, according to which the choice of the indefinite depends on the value for man, while $(60 \mathrm{~b})$ is the representation for a speaker specific reading - here the indefinite has wide scope.

(60) According to Freud, every man unconsciously wants to marry a certain woman.

a. $\forall \mathrm{x}\left[\operatorname{man}(\mathrm{x})->\operatorname{want}\left(\mathrm{x}, \operatorname{marry}\left(\mathrm{x}, \varepsilon_{\mathrm{x}} \mathrm{y}[\operatorname{woman}(\mathrm{y})]\right)\right] \quad\right.$ subject specific

b. $\forall x\left[\operatorname{man}(\mathrm{x})->\operatorname{want}\left(\mathrm{x}, \operatorname{marry}\left(\mathrm{x}, \varepsilon_{\text {speaker }}[\operatorname{woman}(\mathrm{y})]\right)\right]\right.$ speaker specific.

The same contrast can also be represented in the absence of any other operator, such as in (61). Even though the two representations result in the same scope behavior of the indefinite NP, they express a different referential anchoring relation of the indefinite.

(61) A book is missing from the library.

a. $\quad \exists i$ missing_from $\left(\varepsilon_{\mathrm{i}} \mathrm{x}[\operatorname{book}(\mathrm{x})]\right.$, the _library)

non-specific

b. missing_from $\left(\varepsilon_{\text {speaker }} x[\operatorname{book}(x)]\right.$, the_library $)$

specific

\section{Summary}

I argued that the pretheoretical characterization of specificity in (2) above as (i) certainty of the speaker about the identity of the referent, (ii) the referent is fixed, (iii) specific indefinite NP is "scopeless", (iv) specific indefinite NPs are referential terms, and (v) specific indefinite NPs can be paraphrased by a certain, can only describe a restricted set of specific expressions. I showed on observations from Turkish that not all specific indefinites fall under this characterization. The discussion of recent theories of specificity lead to a similar result: Specificity cannot be described in terms of wide scope behavior or in terms of rigid reference. I argued that the reference of a specific expression depends on the "anchor" expression. Once the reference for the anchored is determined, the reference for the specific term is also determined, giving a specific reading of the indefinite.

\section{Bibliography}

Aissen, Judith (2000). Differential Object Marking: Iconicity vs. Economy. Ms. UCSC.

Baker, C. Leroy (1966). Definiteness and Indefiniteness in English. Unpublished Master's Thesis. University of Illinois.

Bossong, Georg (1985). Empirische Universalienforschung. Differentielle Objektmarkierung in den neuiranischen Sprachen. Tübingen: Narr.

Dede, Müserref (1986). Definiteness and Referentiality in Turkish Verbal Sentences. In: D. Slobin \& K. Zimmer (eds.). Studies in Turkish Linguistics. Amsterdam: Benjamins, 147164.

Eco, Umberto (1980). Il nome della rosa. Milano: Bompiani. 
Eco, Umberto (1986). Der Name der Rose. Übersetzt von Burkhart Kroeber. München: Deutscher Taschenbuch Verlag.

Eco, Umberto (1986). Gulun Adi. Turkcesi: Sadan Karadeniz. Istanbul: Can Yayinlari.

Eco, Umberto (1994). The name of the rose. With a postscript by the author. Translated from the Italian by William Weaver. San Diego; New York; London: Harcourt Brace \& Company.

Enç, Mürvet (1991). The Semantics of Specificity. Linguistic Inquiry 22, 1-25.

Farkas, Donka [1981] (1985). Intensional Description and the Romance Subjunctive Mood. New York: Garland.

Farkas, Donka (1995). Specificity and Scope. In: L. Nash \& G. Tsoulas (eds.). Actes du Premier Colloque Langues \& Grammaire. Paris, 119-137.

Farkas, Donka (1997). Dependent Indefinites. In: F. Corblin \& D. Godard \& J.-M. Maradin (eds.). Empirical Issues in Formal Syntax and Semantics. Selected Papers from the Colloque de Syntax et de Sémantique de Paris (CSSP 1995). Bern: Lang, 242-267.

Fillmore, Charles (1967). The Syntax of Preverbs. Glossa 1, 91-125.

Fodor, Janet [1970] (1976). The Linguistic Description of Opaque Contexts. Ph.D. dissertation. MIT, Cambridge/MA. Distributed by Bloomington/IN: Linguistic Club (1976).

Fodor, Janet \& Sag, Ivan (1982). Referential and Quantificational Indefinites. Linguistics and Philosophy 5, 355-398.

Geurts, Bart (2001). Specifics. To appear in K. Schwabe \& K. von Heusinger (eds.). Sentence Type and Specificity. ZAS Papers in Linguistics. Zentrum für Allgemeine Sprachwissenschaft (ZAS). Berlin.

Givón, Talmy (1978). Definiteness and Referentiality. In: J. Greenberg \& C. Ferguson \& E. Moravcsik (eds.). Universals of Human Language. 4 vols. Stanford: Stanford University Press. Vol. 4, 291-330.

Haspelmath, Martin (1997). Indefinite Pronouns. Oxford: Clarendon Press.

Heim, Irene (1982). The Semantics of Definite and Indefinite Noun Phrases. Ph.D. Dissertation. University of Massachusetts, Amherst. Ann Arbor: University Microfilms.

von Heusinger, Klaus (1997). Salienz, und Referenz. Der Epsilonoperator in der Semantik der Nominalphrase und anaphorischer Pronomen. Studia grammatica 43. Berlin: Akademie Verlag.

von Heusinger, Klaus (2000). The Reference of Indefinites. In: K. von Heusinger \& U. Egli (eds.). Reference and Anaphoric Relations. Dordrecht: Kluwer, 247-265.

von Heusinger, Klaus (2001). The Cross-Linguistic Implementations of Specificity. In: K. Jaszczolt \& Ken Turner (eds.). Meanings in Contrast: The Cambridge Papers. Amsterdam; Philadelphia: Benjamins.

Higginbotham, James (1987). Indefinites and Predication. In: E. Reuland \& A. ter Meulen (eds.). The Representation of (In)definiteness. Cambridge/Mass.: MIT Press, 43-70.

Hintikka, Jaakko (1986). The Semantics of 'a certain'. Linguistic Inquiry 17, 331-336.

Jackendoff, Ray (1972). Semantic Interpretation in Generative Grammar. Cambridge/MA: MIT Press.

Johanson, Lars (1977). Bestimmtheit und Mitteilungsperspektive im türkischen Satz. ZDMG (= Zeitschrift der Morgenländischen Gesellschaft) Suppl. 3/2, 1186-1203

Johanson, Lars (1990). Studien zur Türkeitürkischen Grammatik. In: G. Hazai (ed.) Handbuch der Türkischen Sprachwissenschaft. Vol. 1. Wiesbaden: Harrossowitz, 146-301.

Kamp, Hans (1981). A Theory of Truth and Semantic Interpretation. In: J. Groenendijk \& T. Janssen \& M. Stokhof (eds.). Formal Methods in the Study of Language. Amsterdam: Amsterdam Center, 277-322.

Kamp, Hans \& Reyle, Uwe (1993). From Discourse to Logic. Introduction to Modeltheoretic Semantics of Natural Language, Formal Logic and Discourse Representation Theory. Dordrecht: Kluwer.

Karttunen, Lauri (1976). Discourse Referents. In: J. McCawley (ed.). Syntax and Semantics 7: Notes from the Linguistic Underground. New York: Academic Press, 363-385. 
Kasher, Asa \& Gabbay, Dov (1976). On the semantics and pragmatics of specific and nonspecific indefinite expressions. Theoretical Linguistics 2, 145-188.

Kornfilt, Jaklin (1997). Turkish. Routledge: London.

Kratzer, Angelika (1998). Scope or Pseudoscope? Are there Wide-Scope Indefinites. In: S. Rothstein (ed.). Events and Grammar. Dordrecht: Kluwer, 163-196.

Lewis, David (1979). Scorekeeping in a Language Game. In: R. Bäuerle \& U. Egli \& A. von Stechow (eds.). Semantics from Different Points of View. Berlin; Heidelberg; New York: Springer, 172-187.

Lewis, Geoffrey (1967). Turkish Grammar. Oxford: Clarendon.

Ludlow, Peter \& Neale, Stephen (1991). Indefinite Descriptions: In Defense of Russell. Linguistics and Philosophy 14, 171-202.

Lyons, Christopher (1999). Definiteness. Cambridge: Cambridge University Press.

Milsark, Gary (1974). Existential Sentences in English. Ph.D. Diss. MIT, Cambridge/Mass.

Neale, Stephen (1990). Descriptions. Cambridge/Mass.: MIT Press.

Partee, Barbara (1970). Opacity, Coreference, and Pronouns. Synthese 21, 359-385.

Prince, Ellen (1981). On the Inferencing of Indefinite-this NPs. In: A. Joshi \& B. Webber \& I. Sag (eds.). Elements of Discourse Understanding. Cambridge: CUP, 231-250.

Quine, Willard Van Orman (1960). Word and Object. Cambridge/Mass.: MIT Press.

Reimer, Marga (1992). Incomplete Descriptions. Erkenntnis 37, 347-363.

von Stechow, Arnim (2000). Some Remarks on Choice Functions and LF-Movements. In: K. von Heusinger \& U. Egli (eds.). Reference and Anaphoric Relations. Dordrecht: Kluwer, 193-228.

Yeom, Jae-Il (1998). A Presuppositional Analysis of Specific Indefinites: Common Grounds as Structured Information States. Garland Publishing. 